\title{
Salmonella Serotype Paratyphi A
}

National Cancer Institute

\section{Source}

National Cancer Institute. Salmonella Serotype Paratyphi A. NCI Thesaurus. Code C86922.

Any bacterial organism that can be assigned to the genus Salmonella with serotype Paratyphi A. 